\title{
THE GROWTH OF SCROBICULARIA PLANA (DA COSTA) IN THE GWENDRAETH ESTUARY
}

\author{
By J. GreEN \\ Bedford College, University of London
}

(Text-figs. $\mathrm{I}-3$ )

Scrobicularia plana (da Costa) is an abundant inhabitant of intertidal estuarine muds. Populations up to Iooo per $\mathrm{m}^{2}$ have been recorded from the Tamar Estuary (Spooner \& Moore, I940). Similar population densities have been found in the Gwendraeth Estuary in South Wales. In one patch a population of 1025 per $\mathrm{m}^{2}$ was found; the average length of the shells was $30 \mathrm{~mm}$. Individual lengths up to $54 \mathrm{~mm}$ were found in other parts of the estuary. The large size of the specimens from the Gwendraeth prompted an investigation into the rate of growth and the age reached in this locality.

\section{METHODS}

Random samples of Scrobicularia were taken by digging up $\mathrm{I}^{2}$ to a depth of $30 \mathrm{~cm}$ in a region where the average population was 500 per $\mathrm{m}^{2}$. A square metal frame with sides $0.5 \mathrm{~m}$ long and $15 \mathrm{~cm}$ deep was used to prevent mud slipping into the area being sampled. Four samples taken using such a frame made up the total sample of $\mathrm{I} \mathrm{m}^{2}$. Samples were collected in December I953, April I954, August 1954, April I955 and July 1955.

The large specimens were sorted by hand and the small specimens by sieving. A sieve with a mesh of about $6 \mathrm{~mm}$ was used for the early samples, but for the last sample a I mm-mesh sieve was used. As there were some empty shells in the mud, care was taken to collect only the living animals; these were recognized in the field by the slightly protruding mantle lobes and by the presence of an oxidized layer of soil immediately next to the shell even when the animals were taken from a black layer. The specimens were washed and then boiled until the shells gaped widely and the animals dropped out. The shells were then washed and dried; one valve was kept from each. In this way a large number of shells could be stored and their lengths measured at leisure. The length of each shell, to the nearest $\mathrm{mm}$, was written in pencil on its inner surface for future reference and size grouping. In all some 2500 shells were sorted and measured.

Like many other bivalved molluscs, $S$. plana has growth rings on its shell, but often only the last one or two are visible. The earlier growth rings become obliterated and only those left by the last few winters can be found. It is thus 
not possible to determine the age of a shell directly from its growth rings. It is, however, possible to deduce an approximate age by using a series of shells such as that shown in Fig. I. By homologizing the rings on each shell with those on larger and smaller shells, and by working back to progressively smaller shells an estimation can be made of the age of any shell in the series. Examination of the growth rings on some of the large specimens was found to be facilitated by immersion in dilute hydrochloric acid for a short period. Immediately after such treatment the growth rings were very clear, but when the treated shells were stored the rings tended to disappear, and, of course, the treated shells were much more fragile than the untreated shells.

The environmental conditions in the sampling area were studied by measuring the salinity of the water over the area during a tide and by a grade analysis of the soil.

The salinity of the water was estimated with a glass hydrometer; the temperature of the water was measured at the same time and the density reading converted to salinity in \%o using the graph given by Harvey (I945, fig. I2).

The sample of soil for analysis was taken by pushing a stout glass tube into the ground and then lifting it out after clearing the soil away from its sides. The ends of the tube were then closed with rubber bungs. The sample was taken about $3 \mathrm{~h}$ after the tide had uncovered the sampling area so that most of the superficial water had drained away. In the laboratory the soil was pushed out of the tube and chopped into $2 \mathrm{~cm}$ lengths which were weighed and then dried for $\mathrm{I} 6 \mathrm{hr}$ at $105^{\circ} \mathrm{C}$. The subsequent treatment of the samples was identical with that of Holme (1949) except that the treatment with hydrochloric acid to remove carbonates was omitted and sieves with the following meshes were used: $30,60,90$ and I00 I.M.M. In practice it was found that over $95 \%$ of the soil passed through the Ioo I.M.M. sieve.

\section{CONDITIONS IN THE SAMPLING AREA}

The area from which the samples were taken was about $70 \mathrm{~m}$ long, with the length parallel to the edge of the tide, and about $4 \mathrm{~m}$ wide. Neap tides covered the area for about $2 \mathrm{~h}$; on a spring tide the time was increased to about $4 \mathrm{~h}$. The depth of water over the surface of the mud on a neap tide was $0.5 \mathrm{~m}$. The depth over the mud on a spring tide was not measured but is estimated at $2.0 \mathrm{~m}$. The times given for coverage by the tide do not represent the limits of the time available to Scrobicularia for feeding since the surface is poorly drained and still wet for several hours after the tide has receded. The inhalant siphons of Scrobicularia can be seen actively sucking up the surface mud 3 or $4 \mathrm{~h}$ after being uncovered by the tide.

The salinity of the water over the area during a neap tide on 29 July 1955 is shown in Table I. The salinity is probably somewhat higher than usual, due to the hot dry summer and the low state of the river. It was not practic- 
able to measure the salinity during a spring tide, but a few measurements made during the winter $1952-53$ showed a salinity of $18 \%$ at a level just above the sampling area about an hour before high tide. This somewhat lower salinity on a spring tide in winter when compared with a neap tide in summer indicates that the main factor governing salinity over the sampling area is the strength of flow of the river. Other measurements made during winter, as the tide was just uncovering the area, showed a salinity as low as $2 \%$.

TABLE 1. SALINITY OF THE WATER COVERING THE SAMPLING STATION DURING A NEAP TIDE IN JULY 1955

The tide covered the area at I2.44 G.M.T. and uncovered it at I4.45 G.M.T.

$\begin{array}{cccc}\begin{array}{c}\text { Time } \\ \text { (G.M.T.) }\end{array} & \begin{array}{c}\text { Salinity } \\ (\%)\end{array} & \begin{array}{c}\text { Time } \\ \text { (G.M.T.) }\end{array} & \begin{array}{c}\text { Salinity } \\ (\%)\end{array} \\ \text { I2.30 } & 25 & \text { I4.15 } & \text { I2 } \\ \text { 13.00 } & 25 & \text { I4.30 } & \text { II } \\ \text { 13.30 } & 25 & \text { I5.00 } & \text { II } \\ \text { I4.00 } & \text { I5 } & & \end{array}$

TABLE 2. GRADE ANALYSIS OF THE SOIL IN THE SAMPLING AREA

$\begin{array}{cccc} & \begin{array}{c}\text { Fine sand as } \\ \%\end{array} & \begin{array}{c}\text { Silt + clay as } \\ \%\end{array} \\ \text { Depth (cm.) } & \text { water content } & \text { dry weight } & \text { dry weight } \\ \text { I-2 } & 31 & 75 & 24 \\ 2-4 & 28 & 78 & 2 \text { I } \\ 4-6 & 30 & 80 & \text { I9 } \\ 6-8 & 29 & 81 & 17 \\ 8-10 & 27 & 84 & \text { I3 } \\ \text { IO-I2 } & 26 & 88 & \text { I0 } \\ \text { I2-I4 } & 24 & 90 & 8 \\ \text { I4-I6 } & 24 & 90 & 8\end{array}$

Grade analysis of the soil showed that most of the particles passed through the IOO I.M.M. sieve and that of the total dry soil between 8 and $24 \%$ by weight belonged to the silt + clay fraction (Table 2). The most significant variation with depth is in the amount of silt + clay; the surface layers contain three times as much as the soil at a depth of $14-16 \mathrm{~cm}$. The water content, as estimated by the present method, may not be quite the same as that of the mud in situ, but it does give a measure of the water-holding capacity of the soil. It is clear from Table 2 that this capacity increases with increasing silt + clay content, so that the surface layers have a higher water content.

\section{AGE ESTIMATED FROM GROWTH RINGS}

From a series such as that shown in Fig. $\mathrm{I}$ it is possible to construct a growth curve. Such a curve, based on the specimens in Fig. I, is given by the broken line in Fig. 2. The middle part of the curve is based on several specimens at each length (Table 3). Other series of shells give slightly different curves, and if the whole range of variation is considered it is possible to draw up a table giving the upper and lower limits of length for a given year group 
(Table 5). This range of variation, based on the December 1953 sample, is shown in Fig. 2. Attempts to gain greater precision in defining the growth curve do not seem to be very profitable. The details of the curve can only apply to this locality, and further examination of the shells with several

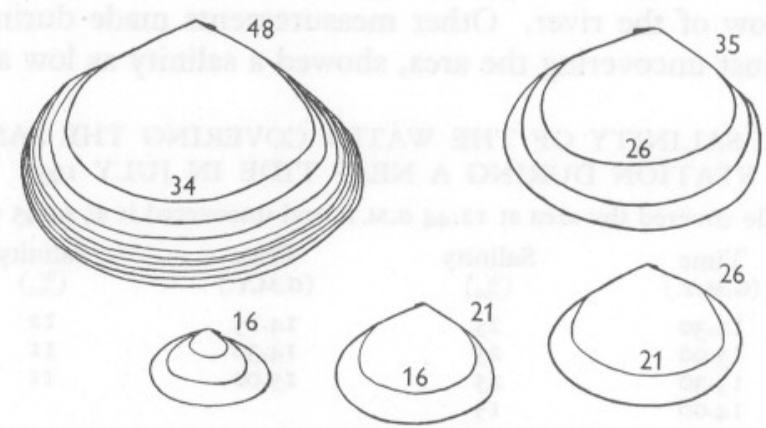

Fig. I. S. plana. Series of shells used to construct the growth curve given by the broken line in Fig. 2. All are drawn to the same scale. The numbers above each shell and on some of the rings give the length in $\mathrm{mm}$.

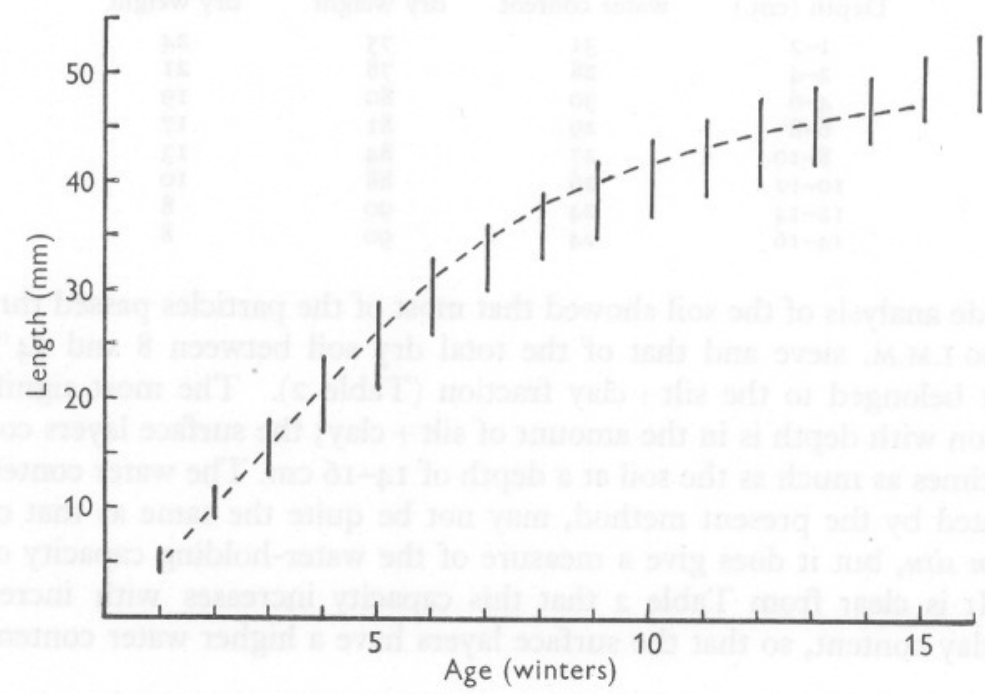

Fig. 2. S. plana. Growth curve constructed using the specimens in Fig. I (broken line), and the range of variation (shown by vertical lines) found in other series of shells.

growth rings often reveals a narrow interval between two wider ones, indicating that some years are better for growth than others.

If the mid-point in the range of variation given for each year group in Table 5 is taken as representative of an 'average' animal of that year the following summary can be given of the growth of Scrobicularia. A length of 
$5 \mathrm{~mm}$ is reached by the first winter. During each of the next two years another $5 \mathrm{~mm}$ is added to the length. Between the third and fourth winters 6 or $7 \mathrm{~mm}$ are added, thereafter the growth rate steadily decreases until the ninth or tenth winter, after which a fairly steady addition of about $2 \mathrm{~mm}$ per year is made.

TABLE 3. GROWTH RINGS ON MEDIUM-SIZED SCROBICULARIA PLANA

Sample collected in December 1953

\begin{tabular}{|c|c|c|c|}
\hline \multirow[b]{2}{*}{$\begin{array}{l}\text { Length of shell } \\
\qquad(\mathrm{mm})\end{array}$} & \multirow[b]{2}{*}{$\begin{array}{c}\text { No. } \\
\text { examined }\end{array}$} & \multicolumn{2}{|c|}{ Mean length of growth rings (mm) } \\
\hline & & Last & $\begin{array}{l}\text { Penultimate } \\
\text { (when visible) }\end{array}$ \\
\hline 2I & ro & 15.4 & - \\
\hline 26 & Io & $21 \cdot 0$ & - \\
\hline 30 & Io & $26 \cdot 4$ & $2 I \cdot 5(4)^{\star}$ \\
\hline 35 & Io & $32 \cdot 2$ & $26.5(7)$ \\
\hline 38 & 5 & $35 \cdot 0$ & $30.0(2)$ \\
\hline
\end{tabular}

* The numbers in parentheses give the number with two growth rings visible.

TABLE 4. GROWTH RINGS ON LARGE SCROBICULARIA PLANA

Sample collected in December 1953

Length $46 \mathrm{~mm}$ with 7 rings between one at $36 \mathrm{~mm}$ and the shell edge Length $46 \mathrm{~mm}$ with 5 rings between one at $38 \mathrm{~mm}$ and the shell edge Length $46 \mathrm{~mm}$ with 5 rings between one at $39 \mathrm{~mm}$ and the shell edge Length $46 \mathrm{~mm}$ with 6 rings between one at $35 \mathrm{~mm}$ and the shell edge Length $46 \mathrm{~mm}$ with 6 rings between one at $33 \mathrm{~mm}$ and the shell edge Length $50 \mathrm{~mm}$ with 7 rings between one at $36 \mathrm{~mm}$ and the shell edge Length $50 \mathrm{~mm}$ with 5 rings between one at $43 \mathrm{~mm}$ and the shell edge Length $50 \mathrm{~mm}$ with 6 rings between one at $37 \mathrm{~mm}$ and the shell edge

TABLE 5. VARIATION IN LENGTH WITH AGE IN SCROBICULARIA PLANA FROM THE GWENDRAETH ESTUARY

$\begin{array}{cccc}\begin{array}{c}\text { Age } \\ \text { (winters) }\end{array} & \begin{array}{c}\text { Length } \\ (\mathrm{mm})\end{array} & \begin{array}{c}\text { Age } \\ \text { (winters) }\end{array} & \begin{array}{c}\text { Length } \\ \text { (mm) }\end{array} \\ \text { I } & 4-6 & 9 & 35-42 \\ 2 & 9-12 & \text { I0 } & 37-44 \\ 3 & 13-18 & \text { II } & 39-46 \\ 4 & 17-24 & \text { 12 } & 40-48 \\ 5 & 21-29 & \text { 13 } & 42-49 \\ 6 & 26-33 & \text { I4 } & 44-50 \\ 7 & 30-36 & \text { I5 } & 46-52 \\ 8 & 33-39 & \text { 16 } & 47-54\end{array}$

Raymont (I955) has studied the early growth of S. plana in Kyle Scotnish, Scotland. Here the shells reach a length of $6 \mathrm{~mm}$ by the first autumn and $16 \mathrm{~mm}$ by the second. This is clearly a much greater increase during the second season than that found in the Gwendraeth, and may be due to the artificial fertilization of Kyle Scotnish. 
Table 5 and Fig. 2 indicate that the age of shells above $20 \mathrm{~mm}$ in length cannot be determined accurately. For instance, a shell with a length of $33 \mathrm{~mm}$ might be 6,7 or 8 years old. When even larger shells are considered the accuracy diminishes still further. A shell with a length of $46 \mathrm{~mm}$ may be anywhere between II and I5 years old. Some idea of the variation in large shells can be deduced from Table 4. Some individuals appear to live for about I8 years.

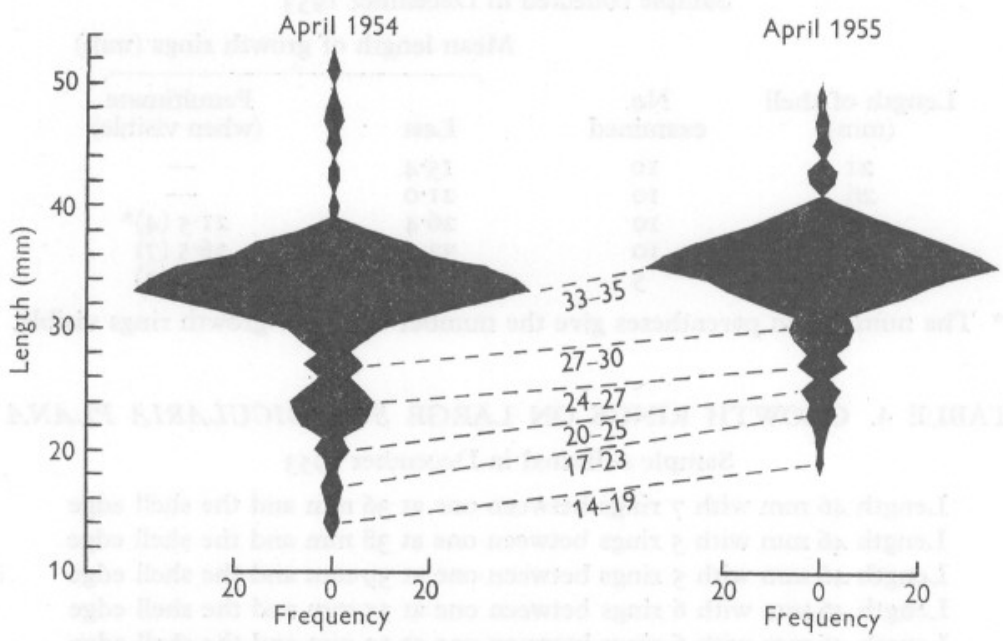

Fig. 3. S. plana. Shift in the peaks of length frequency distribution during one year.

\section{LENGTH FREQUENCY DISTRIBUTION}

In the preceding section it was assumed that the growth rings on the shell are annual rings. In order to test this assumption two samples were taken at a year's interval (April I954 and 1955) to see how the peaks of the length frequency kites moved (Fig. 3). The shifts of the peaks are in fair agreement with the intervals between growth rings and all lie within the range of variation given in Table 5. If the mean size of the whole sample is considered there is a shift from $32 \cdot \mathrm{I}$ to $34.6 \mathrm{~mm}$ which is of a similar order to the increase in length between the seventh and eighth winters.

The earlier samples give no indication of the numbers of small shells so that no idea could be gained of the numbers of spat surviving. The July I955 sample, taken with a I mm-mesh sieve, and sieved very gently so as not to destroy the delicate shells, showed a very small percentage of small shells. Only seven of the 483 shells in the sample were below ro $\mathrm{mm}$ in length. This indicates that there is at present very little successful settlement of spat in the area. The dense adult population is probably the cause of this. Five 
hundred inhalant siphons working in a square metre would make the area a most difficult one for a recently metamorphosed Scrobicularia to survive in. Nevertheless, a few do survive, and it may be that when the present population bulge at a length of $30-40 \mathrm{~mm}$ dies out there will be heavier successful settlements of spat.

\section{SUMMARY}

Populations of Scrobicularia plana with densities up to I025 per $\mathrm{m}^{2}$ are found in the Gwendraeth Estuary.

In a region where the population density was about 500 per $\mathrm{m}^{2}$ it was found that some specimens lived for I6-I8 years and reached a length of $54 \mathrm{~mm}$. An approximate growth curve is given.

There is very little successful settlement of spat in the sampling area; less than $2 \%$ of the shells were under Io $\mathrm{mm}$ in length in July I955. This low figure is attributed to the feeding activities of the dense adult population making the area difficult to settle in.

\section{REFERENCES}

Harvey, H. W., 1945. Recent Advances in the Chemistry and Biology of Sea Water. Cambridge University Press.

Holme, N. A., I949. The fauna of sand and mud banks near the mouth of the Exe Estuary. F. mar. biol. Ass. U.K., Vol. 29, pp. 189-237.

Raymont, J. E. G., I955. The fauna of an intertidal mud flat. Deep-Sea Res., suppl. to Vol. 3, pp. 178-203.

SPOoNer, G. M. \& Moore, H. B., I940. The ecology of the Tamar Estuary. VI. An account of the macrofauna of the intertidal muds. F. mar. biol. Ass. U.K., Vol. 24, pp. $283-330$. 